\title{
Minimally invasive parathyroidectomy versus bilateral neck exploration for primary hyperparathyroidism
}

\section{Primer hiperparatiroidizmde bilateral boyun eksplorasyonuna karşı minimal invaziv paratiroidektomi}

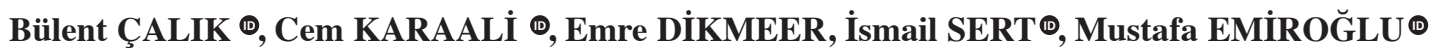 \\ Cengiz AYDIN ${ }^{\oplus}$, Gökhan AKBULUT ${ }^{\oplus}$ \\ Să̆lık Bilimleri Üniversitesi, İzmir Tepecik Ĕ̆itim ve Araştırma Hastanesi, Genel Cerrahi Kliniği, İzmir, Türkiye
}

\begin{abstract}
Objective: Our purpose was to evaluate and compare the results of minimally invasive parathyroidectomy (MIP) with intraoperative parathormone (IOPTH) monitoring and conventional bilateral neck exploration (BNE) without IOPTH monitoring in patients with primary hyperparathyroidism (pHPT).

Methods: Of the 68 patients in the study, 33 patients (48.5\%) underwent MIP with IOPTH monitoring, and 35 patients $(51.5 \%)$ bilateral neck exploration without IOPTH monitoring. Data regarding imaging, localization site, surgery performed, incision size, operative time, adenoma size, postoperative complication, and calcium/PTH measurements obtained at postoperative $6^{\text {th }}$ and $12^{\text {th }}$ months were collected from the patient charts.

Results: A statistically significant difference was not seen between MIP, and BNE groups as for the amount of changes in PTH blood levels according to these two time points of the follow-up period ( $p>0.05)$. When compared with MIP group, in BNE group, blood Ca levels increased to a greater extent also at postoperative 12 . month relative to postoperative 6 . month $(p=0.005)$. As for the comparison of the groups with successful, and failed outcomes, negative effects of male gender, and possession of at least one comorbidity on success rates were detected $(p=0.007$, and $\mathrm{p}=0.002$, respectively). Statistically significant effects of type of surgery, and median size of the adenoma on success rates were not seen $(\mathrm{p}=0.314$, and $\mathrm{p}=0.615$, respectively $)$.

Conclusion: Minimally invasive parathyroidectomy performed with IOPTH analysis, and parathyroidectomy using BNE method have similar, and acceptable success rates.
\end{abstract}

Keywords: Primary hyperparathyroidism, minimally invasive parathyroidectomy, bilateral neck exploration

ÖZ

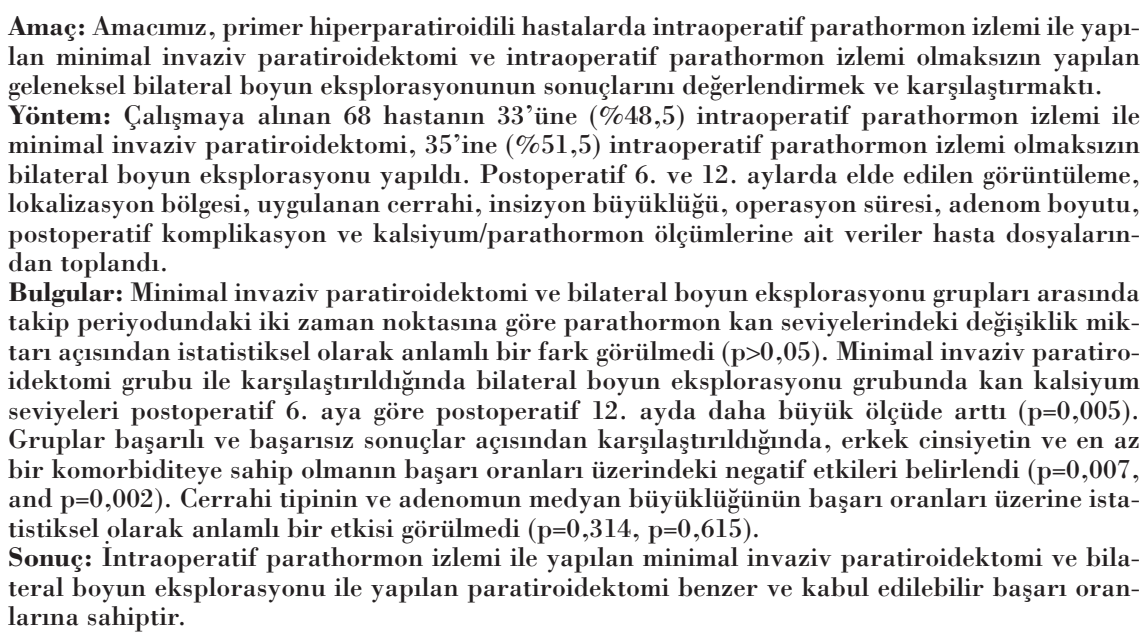

Anahtar kelimeler: Primer hiperparatiroidizm, minimal invaziv paratiroidektomi, bilateral boyun keşfi, intraoperatif parathormon
Alındığı tarih: 07.08 .2018

Kabul tarihi: 10.08 .2018

Yazışma adresi: Uzm. Dr. Bülent Çalık, 100/1 Sokak No:32 Kat:4 Daire:13 Banu Apt. Göztepe Konak - 35290 - İzmir - Türkiye e-mail: calikbulentdr@yahoo.com

\section{Yazarların ORCID bilgileri:}

B.Ç. 0000-0002-9054-1446

C.K. 0000-0003-2743-7360

İ.S. 0000-0001-5190-9124

M.E. 0000-0002-4968-2570

C.A. $0000-0003-4713-2871$

G.A. 0000-0002-3924-5342 


\section{INTRODUCTION}

There is a substantial debate about the most proper surgical approach for primary hyperparathyroidism (pHPT) patients ${ }^{(1)}$. The standard surgical approach involves a bilateral neck exploration (BNE). Minimally invasive parathyroidectomy (MIP) involves the resection of one parathyroid gland, preoperatively localized with radiological techniques.

Minimally invasive surgery for primary hyperparathyroidism depends on precise localization of adenoma preoperatively with sestamibi-technetium $99 \mathrm{~m}$ scintigraphy (sestamibi) and ultrasound (US) and the availability of intraoperative parathormone (IOPTH) monitoring to determine a decrease of PTH concentration (if any) during surgery ${ }^{(2)}$. When intraoperative PTH levels decrease by more than $50 \%$, successful exploration is assured with a predictive cure rate of at least $95 \%$ or greater ${ }^{(3)}$. Bilateral neck exploration with detection of four parathyroid glands and removal of the hyperfunctioning gland has been accepted as 'gold standard' for the pHPT treatment ${ }^{(4)}$. Nevertheless, 80-90 \% of pHPT patients have a solitary adenoma of the parathyroid gland, and the excision of only one gland is mandatory for the treatment of these patients ${ }^{(4)}$.

Our purpose was to evaluate and compare the results of MIP with IOPTH monitoring and BNE without IOPTH monitoring in patients with $\mathrm{pHPT}$ in a certain period of surveillance.

\section{MATERIALS and METHODS}

Study Design: The study has been conducted in accordance with the principles of the Helsinki Declaration and approved by the local Institutional Review Board (20/2016).

A retrospective study of 68 consecutive surgerynaive patients with biochemically proven $\mathrm{pHPT}$ treated at our institution from January 2008 to December 2015 was performed. Information regarding imaging, localization site, the procedure performed, incision size, operative time, adenoma size, postoperative complication, and calcium/PTH mea- surements obtained at postoperative $6^{\text {th }}$ and $12^{\text {th }}$ months were collected from the patient charts.

Of the 68 patients in the study, 33 patients (48.5\%) underwent MIP with IOPTH monitoring, and 35 patients $(51.5 \%)$ bilateral neck exploration without IOPTH monitoring. All patients had sestamibi scan and US for the localization of parathyroid adenomas. A total of 33 patients with a single enlarged parathyroid gland were eligible for inclusion in the MIP Group. A total of 35 patients who had more than one gland (or none) localized during preoperative period , or patients with concomitant thyroid disease requiring both parathyroidectomy and thyroidectomy were eligible for inclusion in the BNE Group.

Patients with hereditary HPT (multiple endocrine neoplasia (MEN) 1 and 2, non-MEN-related familial HPT), suspicion of involvement of multiple parathyroid glands on sestamibi scanning, previous neck exploration for thyroid disorders, anticipated or planned simultaneous thyroid operations, and allergy to drugs used for local anesthesia, as well as those who could not fully comprehend the information given or who rejected confirmation to participate were excluded from the study ${ }^{(5)}$. Patients aged less than 18 years, those with a hypercalcemic crisis and high-risk patients (American Society of Anesthesiologists grade IV) were also not included in the study.

PTH levels above $69 \mathrm{pg} / \mathrm{ml}$ and serum calcium levels above $10.6 \mathrm{mg} / \mathrm{dL}$ measured at 6 , and 12 . months were defined as procedural failure.

Statistical Analysis: Data were analyzed using the IBM Statistical Package for Social Sciences v21 (SPSS Inc., Chicago, IL, USA). Data are expressed as mean $\pm \mathrm{SD}$ or median (interquartile range), as appropriate. Parametric tests (Student's t test) were applied to data of normal distribution and non-parametric tests (Mann-Whitney) were applied to data of questionably normal distribution. All differences associated with a chance probability of $\leq .05$ were considered statistically significant. Numeric data and percentages related to patient's features, and prognostic characteristics, and necessary cross comparisons were presented as descriptive statistics. A univariate analytical method examined the correlation 
between prognostic factors and survival rates. Survival curves were estimated using the KaplanMeier method. A univariate analysis of potential prognostic factors was performed with the log-rank test for categorical factors and with the univariate Cox analysis for continuous variables Parameters with a p-value of $<0.15$ at the univariate step were included in the multivariate regression Cox proportional hazards model.

\section{RESULTS}

Demographic and clinical characteristics of the cases according to groups are shown in Table 1. A statistically significant difference was not seen among groups as for mean ages $(p=0.145)$, gender distribution $(p=0.191)$, the percentage of symptomatic cases $(\mathrm{p}=0.902)$, postoperative complicatiDemographic and clinical characteristics of the cases according to groups are shown in Table 1. A statistically significant difference was not seen among groups as for mean ages $(\mathrm{p}=0.145)$, gender distribution $(\mathrm{p}=0.191)$, the percentage of symptomatic cases $(\mathrm{p}=0.902)$, postoperative complications $(\mathrm{p}=0.493)$, and median follow-up period ( $\mathrm{p}=0.476)$. In the MIP group, the incidence of concomitant diseases $(\mathrm{p}=0.013)$, and length of the median incision in the BNE group statistically significantly increased $(\mathrm{p}<0.001)$. The median size of the adenoma was statistically significantly lower in the BK group $(\mathrm{p}<0.001)$.

Intragroup PTH and $\mathrm{Ca}$ levels are shown in Table 2. Intraoperative, postoperative 6., and 12. monthblood PTH levels in MIP and BNE groups were statistically significantly different when compared with
Table 1. Clinical and demographic details of the patient groups.

\begin{tabular}{lccc}
\hline & $\begin{array}{c}\text { MIP Group } \\
(\mathbf{n = 3 3})\end{array}$ & $\begin{array}{c}\text { BNE Group } \\
(\mathbf{n = 3 5})\end{array}$ & p Value \\
\hline Age (years) & $51.3 \pm 15.5$ & $56.1 \pm 12.8$ & $0.145^{\dagger}$ \\
Sex ratio (M/F) & $4 / 29$ & $1 / 34$ & $0.191^{\ddagger}$ \\
Accompanying disease & $16 / 33(48.5 \%)$ & $7 / 35(20.0 \%)$ & $0.013^{\ddagger}$ \\
Symptomatic disease & $26 / 33(78.8 \%)$ & $28 / 35(80.0 \%)$ & $0.902^{\ddagger}$ \\
Incision size (cm) & $3.2(2.5-5.1)$ & $6,0(3.0-6.5)$ & $<0.001^{\$}$ \\
Adenoma size (mm) & $20(10-40)$ & $15(6-30)$ & $<0.001^{\$}$ \\
Postoperative complication & - & $2(\% 5.7)$ & $0.493^{\ddagger}$ \\
Follow-up (months) & $21(12-90)$ & $20(12-85)$ & $0.476^{\$}$ \\
& & & \\
\hline
\end{tabular}

${ }^{7}$ Student's t test, ${ }^{*}$ Fisher's exact test, ${ }^{9}$ Ki-Square test, ${ }^{\$}$ Mann-Whitney U test. $M I P=$ Minimally invasive parathyroidectomy; $B N E=$ Bilateral neck exploration; $M=$ Male $;$ F=Female

Table 2. Intragroup PTH, and Ca levels based on the times of measurement during follow-up period.

\begin{tabular}{|c|c|c|c|}
\hline & & MIP Group (n=33) & BNE Group (n=35) \\
\hline \multirow{5}{*}{$\begin{array}{l}\mathrm{PTH} \\
(\mathrm{pg} / \mathrm{ml})\end{array}$} & Preoperative & $248.0(94.0-2174.0)^{\mathrm{a}, \mathrm{b}, \mathrm{c}}$ & $198.0(79.0-904.0)^{\mathrm{a}, \mathrm{b}, \mathrm{c}}$ \\
\hline & Intraoperative & $34.3(3.0-123.8)^{\mathrm{a}}$ & $43.0(5.0-93.2)^{\mathrm{a}}$ \\
\hline & $\begin{array}{l}\text { Postoperative } \\
6^{\text {th }} \text { month }\end{array}$ & $50.5(10.5-226.0)^{\mathrm{b}}$ & $42.3(0.2-207.0)^{\mathrm{b}}$ \\
\hline & $\begin{array}{l}\text { Postoperative } \\
12^{\text {th }} \text { month }\end{array}$ & $45.0(5.2-117.0)^{\mathrm{c}}$ & $33.9(4.7-181.0)^{\mathrm{c}}$ \\
\hline & $\mathrm{p}$ Value $\dagger$ & $<0.001$ & $<0.001$ \\
\hline \multirow{4}{*}{$\begin{array}{l}\mathrm{Ca} \\
(\mathrm{mg} / \mathrm{dl})\end{array}$} & Preoperative & $11.6(10.5-17)^{\mathrm{b}, \mathrm{c}}$ & $11.6(8.5-14.1)^{\mathrm{b}, \mathrm{c}}$ \\
\hline & $\begin{array}{l}\text { Postoperative } \\
6^{\text {th }} \text { month }\end{array}$ & $9.5(8.0-12.0)^{\mathrm{b}}$ & $8.7(5.8-10.5)^{\mathrm{b}, \mathrm{d}}$ \\
\hline & $\begin{array}{l}\text { Postoperative } \\
12^{\text {th }} \text { month }\end{array}$ & $9.4(8.1-10.7)^{\mathrm{c}}$ & $9.3(7.4-11.0)^{\mathrm{c}, \mathrm{d}}$ \\
\hline & $\mathrm{p}$ Value $\dagger$ & $<0.001$ & $<0.001$ \\
\hline
\end{tabular}

${ }^{\dagger}$ Friedman test, ${ }^{a}:$ Preoperative vs. Intraoperative $(p<0,001),{ }^{b}:$ Preoperative vs. Postoperative $6^{\text {th }}$ month $(p<0,001),{ }^{c}$ : Preoperative vs. Postoperative $12^{\text {th }}$ month $(p<0,001),{ }^{d}$ : Postoperative $6^{\text {th }}$ month vs. Postoperative $12^{\text {th }}$ month $(p<0,001)$. MIP=Minimally invasive parathyroidectomy; $B N E=$ Bilateral neck exploration

preoperative levels $(\mathrm{p}<0.001$ for both groups). Intraoperative, postoperative 6., and 12. month-blood Ca levels in MIP, and BNE groups were statistically significantly different when compared with preopera-

Table 3. Intergroup comparisons of changes in PTH, and Ca levels between any time points during follow-up period.

\begin{tabular}{|c|c|c|c|c|}
\hline & & MIP Group (n=33) & BNE Group $(n=35)$ & p Value ${ }^{\dagger}$ \\
\hline PTH (pg/ml) & $\begin{array}{l}\text { Preoperative vs. Intraoperative } \\
\text { Preoperative vs. Postoperative } 6^{\text {th }} \text { month } \\
\text { Preoperative vs. Postoperative } 12^{\text {th }} \text { month } \\
\text { Intraoperative vs. Postoperative } 6^{\text {th }} \text { month } \\
\text { Intraoperative vs. Postoperative } 12^{\text {th }} \text { month } \\
\text { Postoperative } 6^{\text {th }} \text { month vs. Postoperative } 12^{\text {th }} \text { month }\end{array}$ & $\begin{array}{l}-224.7(-2171.0--58.5) \\
-222.4(-1948.0--33.2) \\
-222.4(-2063.8--3.6) \\
5.1(-59.0-223.0) \\
-0.09(-74.0-107.2) \\
-2.0(-115.8-79.9)\end{array}$ & $\begin{array}{l}-154.8(-852.4--20.8) \\
-161.0(-868.6--24.0) \\
-148.5(-878.2--36.6) \\
-5.3(-89.6-158.0) \\
-7.4(-67.5-131.6) \\
-4.8(-176.1-56.1)\end{array}$ & $\begin{array}{l}0.078 \\
0.187 \\
0.158 \\
0.450 \\
0.121 \\
0.907\end{array}$ \\
\hline $\mathrm{Ca}(\mathrm{mg} / \mathrm{dl})$ & $\begin{array}{l}\text { Preoperative vs. Postoperative } 6^{\text {th }} \text { month } \\
\text { Preoperative vs. Postoperative } 12^{\text {th }} \text { month } \\
\text { Postoperative } 6^{\text {th }} \text { month vs. Postoperative } 12^{\text {th }} \text { month }\end{array}$ & $\begin{array}{l}-2.1(-8.2--1.0) \\
-2.3(-7.2--0.8) \\
-0.3(-2.2-1.6)\end{array}$ & $\begin{array}{l}-3.0(-5.5--0.5) \\
-2.4(-5.1-0.0) \\
0.6(-1.3-2.4)\end{array}$ & $\begin{array}{l}0.004 \\
0.759 \\
0.005\end{array}$ \\
\hline
\end{tabular}

Mann Whitney U test. 
tive levels ( $p<0.001$ for both groups). Besides, in BNE group $\mathrm{Ca}$ levels were statistically significantly higher at postoperative 12 . month relative to postoperative 6 . month $(\mathrm{p}<0.001)$.

Intergroup comparison of changes in $\mathrm{PTH}$, and $\mathrm{Ca}$ levels between any of two periods of monitorization are shown in Table 3. A statistically significant difference was not seen between MIP, and BNE groups as for the amount of changes in PTH blood levels according to these two time points of the follow-up period $(\mathrm{p}>0.05)$. In the BNE group, when compared with preoperative levels, at postoperative 6 . month blood $\mathrm{Ca}$ levels decreased statistically significantly to a greater extent relative to MIP group ( $\mathrm{p}=0.004$ ). Besides when compared with MIP group, in BNE group, blood Ca levels increased to a greater extent also at postoperative 12 . month relative to postoperative 6 . month $(\mathrm{p}=0.005)$.

Comparison of the groups with successful and failed outcomes is shown in Table 4. Negative effects of male gender and possession of at least one comor-

Table 4. Demographic and clinical characteristics of the cases according to the groups with successful, and failed outcomes as for PTH levels at the end of 6 . months.

\begin{tabular}{lccc}
\hline & $\begin{array}{c}\text { Successful } \\
(\mathbf{n = 5 3})\end{array}$ & $\begin{array}{c}\text { Unsuccessful } \\
(\mathbf{n = 1 5})\end{array}$ & p Value $^{\#}$ \\
\hline Age (years) & $54.2 \pm 12.9$ & $51.6 \pm 18.7$ & $0.617^{\dagger}$ \\
Sex ratio (M/F) & $1 / 52$ & $4 / 11$ & $0.007^{\ddagger}$ \\
Accompanying disease & $13(\% 24.5)$ & $10(\% 66.7)$ & $0.002^{\ddagger}$ \\
Groups MIP & $24(\% 45.3)$ & $9(\% 60.0)$ & 0.314 \\
\multicolumn{1}{|c}{ BNE } & $29(\% 54.7)$ & $6(\% 40.0)$ & \\
Adenoma size (mm) & $18(6-40)$ & $20(10-30)$ & $0.615^{\varsigma}$ \\
\hline
\end{tabular}

${ }^{\top}$ Student's $t$ test, ${ }^{*}$ Fisher's exact test, ${ }^{\prime}$ Ki-Square test, ${ }^{\$}$ Mann Whitney $U$ test, "The P value that indicates statistical significance after the Bonferroni correction is .0125, MIP=Minimally invasive parathyroidectomy; $B N E=$ Bilateral neck exploration

Table 5. Demographic and clinical characteristics of the cases according to the groups with successful, and failed outcomes as for Ca levels at the end of 6 . months.

\begin{tabular}{lccc}
\hline & $\begin{array}{c}\text { Successful } \\
(\mathbf{n = 6 4 )}\end{array}$ & $\begin{array}{c}\text { Unsuccessful } \\
(\mathbf{n = 4})\end{array}$ & $\mathbf{p ~ V a l u e}^{\mathrm{s}}$ \\
\hline Age (years) & $53.2 \pm 14.0$ & $61.5 \pm 19.3$ & $0.261^{\dagger}$ \\
Sex ratio (M/F) & $5 / 59$ & $0 / 4$ & $>0.999^{\ddagger}$ \\
Accompanying disease & $21(\% 32.8)$ & $2(\% 50.0)$ & $0.599^{\ddagger}$ \\
Groups MIP & $29(\% 45.3)$ & $4(\% 100.0)$ & $0.050^{\ddagger}$ \\
$\quad$ BNE & $35(\% 54.7)$ & $0(\% 0.0)$ & \\
Adenoma size (mm) & $18(6-40)$ & $30(15-30)$ & $0.117^{\ddagger}$ \\
\hline
\end{tabular}

'Student's $t$ test, ${ }^{*}$ Fisher's exact test, "Mann Whitney U test

${ }^{\$}$ The P value that indicates statistical significance after the Bonferroni correction is .0167 bidity on success rates were detected $(\mathrm{p}=0.007$, and $\mathrm{p}=0.002$ ). Statistically significant effects of type of surgery, and median size of the adenoma on success rates were not seen $(p=0.314$, and $p=0.615)$. Since in univariate analysis, statistically significant effect of type of surgery on success rates was not seen. When adjustments were made for other probable risk factors, the significance of the impact of the type of surgery on success rates (if any) could not be investigated in multivariate logistic regression.

The comparisons of the groups with successful, and failed outcomes as for blood Ca levels at the end of 6 . and 12. months, and as for blood PTH levels at the end of 12. months are shown in Tables 5, 6, and 7, respectively. A statistically significant intergroup difference was not seen as for mean ages, gender distribution, comorbid diseases, type of surgery, and median size of adenoma $(p>0,05)$. As a result of univariate analyses, none of those above-mentioned variables had any statistically significant effect on success rates, so bivariate logistic regression analysis could not be performed.

Table 6. Demographic and clinical characteristics of the cases according to the groups with successful, and failed outcomes as for PTH levels at the end of 12 . months.

\begin{tabular}{lccc}
\hline & $\begin{array}{c}\text { Successful } \\
(\mathbf{n = 5 9})\end{array}$ & $\begin{array}{c}\text { Unsuccessful } \\
(\mathbf{n = 9})\end{array}$ & p Value \\
\hline Age (years) & $52.7 \pm 14.9$ & $59.6 \pm 8.2$ & $0.186^{\dagger}$ \\
Sex ratio (M/F) & $5 / 54$ & $0 / 9$ & $>0.999^{\ddagger}$ \\
Accompanying disease & $18(\% 30.5)$ & $5(\% 55.6)$ & $0.255^{\ddagger}$ \\
Groups MIP & $27(\% 45.8)$ & $6(\% 66.7)$ & $0.299^{\ddagger}$ \\
\multicolumn{1}{c}{ BNE } & $32(\% 54.2)$ & $3(\% 33.3)$ & \\
Adenoma size (mm) & $18(6-40)$ & $30(10-40)$ & $0.321^{\ddagger}$ \\
\hline
\end{tabular}

${ }^{\top}$ Student's t test, ${ }^{*}$ Fisher's exact test, "Mann Whitney U test

"The P value that indicates statistical significance after the Bonferroni correction is .0125

Table 7. Demographic and clinical characteristics of the cases according to the groups with successful, and failed outcomes as for Ca levels at the end of 12 . months.

\begin{tabular}{lccc}
\hline & $\begin{array}{c}\text { Successful } \\
(\mathbf{n = 6 5})\end{array}$ & $\begin{array}{c}\text { Unsuccessful } \\
(\mathbf{n = 3})\end{array}$ & p Value \\
\hline Age (years) & $53.4 \pm 14.5$ & $58.7 \pm 9.3$ & $0.538^{\dagger}$ \\
Sex ratio (M/F) & $5 / 60$ & $0 / 3$ & $>0.999^{\ddagger}$ \\
Accompanying disease & $22(\% 33.8)$ & $1(\% 33.3)$ & $>0.999^{\ddagger}$ \\
Groups MIP & $31(\% 47.7)$ & $2(\% 66.7)$ & $0.608^{\ddagger}$ \\
$\quad$ BNE & $34(\% 52.3)$ & $1(\% 33.3)$ & \\
Adenoma size (mm) & $20(6-40)$ & $15(10-30)$ & $0.651^{\ddagger}$ \\
& & & \\
\hline
\end{tabular}

${ }^{\dagger}$ Student's t test, ${ }^{*}$ Fisher's exact test, ${ }^{9}$ Mann Whitney U test

${ }^{\$}$ The $P$ value that indicates statistical significance after the Bonferroni correction is .0167 


\section{DISCUSSION}

Controversy continues to exist as to which operative approach should be considered as the standard surgical treatment for pHPT. With the advent of improved preoperative parathyroid localization studies, increased availability of IOPTH monitoring, and the predominance of single-gland disease in most patients with pHPT, MIP has become the alternative to conventional BNE.

Combined sestamibi scan, and US may 94-99\% improve the precision of localization of a solitary adenoma ${ }^{(6,7)}$. When concordant sestamibi scan and US have been reported to have an operative success rate close to $99 \%$, preventing the need for IOPTH monitoring ${ }^{(5-8)}$. Although studies reveal outstanding results in this subgroup of very particular patients with concordant localizing studies, this selective approach considerably restricts the number of suitable patients for MIP. Preoperative sestamibi scan and US have been shown to be concordant only in 50-60\% of the cases, leaving an excessive number of patients with no definitive localization ${ }^{(9)}$. Discordance between sestamibi scan and US has been described in $38 \%$ of the patients treated by parathyroidectomy with an $11 \%$ rate of multiglandular disease. Advantages of MIP include improved esthetic outcomes with minor incisions, reduced postoperative pain, shorter surgery time, reduced hospitalization, and fast postoperative recovery with more than $95 \%$ treatment success rate similar to $\mathrm{BNE}{ }^{(10)}$. IOPTH monitoring is a significant improvement in the management of primary hyperparathyroidism, and a surgical adjunct to reveal the excision of all hyperfunctioning parathyroid tissue. First applied routinely by George Irvin, IOPTH monitoring minimizes the need to detect all four parathyroid glands ${ }^{(11,12)}$. The intraoperative principle for effective parathyroidectomy firstly defined by Irvin is a reduction of PTH levels more than 50\% from the highest preincision (or preexcision) PTH level in peripheral blood samples obtained ten minutes after removal of all pathological parathyroid tissue ${ }^{(11-13)}$.

The conventional approach in the surgical management of primary hyperparathyroidism is BNE that typically necessitates the detection of four parathyroid glands. When performed by skilled specialists, the treatment rate for BNE is over $95 \%$ with a complication rate varying between $1 \%$ and $4 \%{ }^{(14,15)}$. When patients have more than one gland (or none) located during preoperative studies, BNE should be taken into account. BNE is also indicated in patients with secondary or tertiary hyperparathyroidism. In patients with related thyroid pathology necessitating combined parathyroidectomy and thyroidectomy, and in cases of parathyroid cancer, BNE is performed.

The success of MIP has been confirmed by numerous studies with treatment and complication rates comparable to BNE ${ }^{(16-18)}$. Udelsman et al. ${ }^{(17)}$ studied 656 patients older than 11 years in which 255 underwent MIP and $401 \mathrm{BNE}$ with cure rates ranging between $99 \%$ and $97 \%$. Irvin et al. ${ }^{(18)}$ studied 718 patients older than 34 years and revealed that the cure rates for MIP and BNE were $97 \%$ and $94 \%$, respectively. In a 5-year follow-up of a randomized controlled trial, MIP presented the similar long-term results as BNE in primary hyperparathyroidism patients ${ }^{(19)}$. All the studies concluded that MIP was an effective alternative to BNE for most patients with primary hyperparathyroidism.

Presently, there are few long-term data to compare the operative success rates between MIP and BNE. Siperstein et al. simulated MIP in 916 patients with primary hyperparathyroidism, by using preoperative sestamibi scan and US for parathyroid localization and intraoperative IOPTH monitoring ${ }^{(20)}$. Afterward, BNE was performed in all these patients, showing $16 \%$ of patients with further enlarged glands, which arised the distress for longer-term failure or recurrence rate for MIP may be greater than described in reports of initial outcomes ${ }^{(20)}$. Further reports, however, have suggested otherwise and showed that MIP resulted in the long-term, and permanent surgical achievement comparable to BNE.

In our cases, median size of the adenomas was statistically significantly lower in the group that underwent BNE which we attributed to the difficulty in the detection of smaller adenomas using imaging modalities. As postoperative complication in two 
cases in the BNE group, presumably symptomatic and transient hypocalcemia developed secondary to the exploration of all parathyroid glands in the BNE group. During the postoperative period, this condition resolved with medical treatment. In one patient in the BNE group, a hyperplasic gland other than an adenomatous gland was excised. In this patient, PTH level decreased $50 \%$ at 15 . minutes. Intragroup PTH levels were analyzed at various time points during the follow-up period. In the MIP group at 6 . postoperative month they were above $69 \mathrm{pg} / \mathrm{ml}$ in 9 patients. However, in BNE group in only 6 patients increased PTH levels were detected. Whereas at postoperative 1. year 6 patients in MIP and 3 patients in BNE group TPH levels were higher than $69 \mathrm{pg} / \mathrm{ml}$. At postoperative 6. month Ca levels were higher than $10.6 \mathrm{mg} / \mathrm{dl}$ in 4 patients in MIP group. While at postoperative 12. month higher $\mathrm{Ca}$ levels were detected in 2 patients in MIP, and 1 patient in BNE group.

\section{CONCLUSION}

Minimally invasive parathyroidectomy performed with IOPTH analysis, and parathyroidectomy using BNE method have similar, and acceptable success rates.

\section{Acknowledgement}

None

\section{REFERENCES}

1. Madkhali T, Alhefdhi A, Chen H, Elfenbein D. Primary hyperparathyroidism. Ulus Cerrahi Derg 2016;32:58-66. https://doi.org/10.5152/UCD.2015.3032

2. Gracie D, Hussain SS. Use of minimally invasive parathyroidectomy techniques in sporadic primary hyperparathyroidism: systematic review. J Laryngol Otol. 2012;126:221-227. https://doi.org/10.1017/S0022215111002908

3. Wong W, Foo FJ, Lau MI, Sarin A, Kiruparan P. Simplified minimally invasive parathyroidectomy: a series of 100 cases and review of the literature. Ann R Coll Surg Engl. 2011;93:290-293.

https://doi.org/10.1308/003588411X571836

4. Moalem J, Guerrero M, Kebebew E. Bilateral neck exploration in primary hyperparathyroidism--when is it selected and how is it performed? World J Surg. 2009;33:2282-2291. https://doi.org/10.1007/s00268-009-9941-5

5. Bergenfelz A, Kanngiesser V, Zielke A, Nies C, Rothmund M. Conventional bilateral cervical exploration versus open minimally invasive parathyroidectomy under local anaesthesia for primary hyperparathyroidism. British Journal of Surgery: Incorporating European Journal of Surgery and
Swiss Surgery. 2005;92(2):190-197.

https://doi.org/10.1002/bjs.4814

6. Haber RS, Kim CK, Inabnet WB. Ultrasonography for preoperative localization of enlarged parathyroid glands in primary hyperparathyroidism: comparison with $(99 \mathrm{~m})$ technetium sestamibi scintigraphy. Clin Endocrinol. 2002;57:241-249. https://doi.org/10.1046/j.1365-2265.2002.01583.x

7. Gawande AA, Monchik JM, Abbruzzese TA, Iannuccilli JD, Ibrahim SI, Moore FD Jr. Reassessment of parathyroid hormone monitoring during parathyroidectomy for primary hyperparathyroidism after 2 preoperative localization studies. Arch Surg. 2006;141:381-384; discussion 384. https://doi.org/10.1001/archsurg.141.4.381

8. Mihai R, Palazzo FF, Gleeson FV, Sadler GP. Minimally invasive parathyroidectomy without intraoperative parathyroid hormone monitoring in patients with primary hyperparathyroidism. Br J Surg. 2007;94:42-47. https://doi.org/10.1002/bjs.5574

9. Lew JI, Solorzano CC, Montano RE, Carneiro-Pla DM, Irvin GL 3rd. Role of intraoperative parathormone monitoring during parathyroidectomy in patients with discordant localization studies. Surgery. 2008;144:299-306.

https://doi.org/10.1016/j.surg.2008.03.039

10. Bellantone R, Raffaelli M, DE Crea C, Traini E, Lombardi CP. Minimally-invasive parathyroid surgery. Acta Otorhinolaryngol Ital. 2011;31:207-215.

11. Irvin GL, Prudhomme DL, Deriso GT, Sfakianakis G, Chandarlapaty SK. A new approach to parathyroidectomy. Ann Surg. 1994;219:574-581. https://doi.org/10.1097/00000658-199405000-00015

12. Irvin GL, Sfakianakis G, Yeung L, Deriso GT, Fishman LM, Molinari AS, Foss JN. Ambulatory parathyroidectomy for primary hyperparathyroidism. Arch Surg. 1996;131:1074-1078. https://doi.org/10.1001/archsurg.1996.01430220068015

13. Carneiro DM, Solorzano CC, Nader MC, Ramirez M, Irvin GL 3rd. Comparison of intraoperative iPTH assay (QPTH) criteria in guiding parathyroidectomy: which criterion is the most accurate? Surgery. 2003;134:973-981. https://doi.org/10.1016/j.surg.2003.06.001

14. Kaplan EL, Yashiro T, Salti G. Primary hyperparathyroidism in the 1990s: choice of surgical procedures for this disease. Ann Surg. 1992;215:300-317. https://doi.org/10.1097/00000658-199204000-00002

15. Allendorf J, DiGorgi M, Spanknebel K, Inabnet W, Chabot J, Logerfo P. 1112 consecutive bilateral neck explorations for primary hyperparathyroidism. World J Surg. 2007;31:2075-2080. https://doi.org/10.1007/s00268-007-9068-5

16. Chen H, Pruhs Z, Starling JR, Mack E. Intraoperative parathyroid hormone testing improves cure rates in patients undergoing minimally invasive parathyroidectomy. Surgery. 2005;138:583-590.

https://doi.org/10.1016/j.surg.2005.06.046

17. Udelsman R. Six hundred fifty-six consecutive explorations for primary hyperparathyroidism. Ann Surg. 2002;235:665-672. https://doi.org/10.1097/00000658-200205000-00008

18. Lew JI, Solorzano CC. Surgical management of primary hyperparathyroidism: state of the art. The Surgical Clinics of North America. 2009;89(5):1205-1225. https://doi.org/10.1016/j.suc.2009.06.014

19. Westerdahl J, Bergenfelz A. Unilateral versus bilateral neck exploration for primary hyperparathyroidism: five-year follow-up of a randomized controlled trial. Ann Surg. 2007;246:976-981. https://doi.org/10.1097/SLA.0b013e31815c3ffd

20. Siperstein A, Berber E, Barbosa GF, Tsinberg M, Greene AB, Mitchell J, Milas M. Predicting the success of limited exploration for primary hyperparathyroidism using ultrasound, sestamibi and intraoperative parathyroid hormone: analysis of 1158 cases. Ann Surg. 2008;248:420-428. https://doi.org/10.1097/SLA.0b013e3181859f71 